\title{
IMPACT OF BLOCKCHAIN TECHNOLOGY ON THE CONTINUOUS AUDITING: MEDIATING ROLE OF TRANSACTION COST THEORY
}

\author{
Zsofia Barandi, University of North Dakota, zsofia.barandi@ndus.edu \\ Assion Lawson-Body, University of North Dakota, assion.lawsonbody@und.edu \\ Laurence Lawson-Body, University of North Dakota, laurence.lawsonbody@und.edu \\ Lori Willoughby, Minot State University, lori.willoughby@minotstateu.edu
}

\begin{abstract}
Blockchain is one of the most significant emerging technologies today. Anecdotal evidence suggested that blockchain technology will transform auditing by enabling continuous auditing. However, there is little empirical knowledge of the blockchain implications on the audit profession. The objective of this paper is to explore, through the lens of transaction costs theory, the impact of blockchain technology on the continuous auditing. A proposed research model will be tested using survey data that will be collected from audit firms. The collected data will be processed using $R$ statistical software that is appropriate to data analytics. The expected results should indicate that auditors still need to use professional judgment and gather evidence for assertions factors that blockchain technology does not address. Furthermore, regardless of the role they might choose to fulfill, auditors must keep up to date with the technology if they are to stay in-demand in the world of blockchain.
\end{abstract}

Keywords: Blockchain, Audit, Transaction Cost Theory, distributed database, peer-to-peer transmission.

\section{INTRODUCTION}

Blockchain technology has been an increasingly prominent subject matter in the business world (Ahluwalia, Mahto, \& Guerrero, 2020; Wang, Qin, \& Zhao, 2020; Fan, Bao, \& Liu, 2020; Putz, Menges, Pernul, 2019; Muzammal, Qu, Nasrulin, 2019; Schmidt \& Wagner, 2019). The blockchain platforms have the potential to disrupt various industries including the audit procession (Ahluwalia, Mahto, \& Guerrero, 2020). The cryptocurrencies are based on a set of technologies commonly referred to as blockchain technology (Ahluwalia, Mahto, \& Guerrero, 2020). For instance, the concept of bitcoin, is a type of cryptocurrency without the existence of a trusted party, which uses the blockchain framework to conduct its transactions (Bible, Raphael, \& Riviello, 2017; Wang, Qin, \& Zhao, 2020). In general, blockchains are a link list of data blocks, where each block is linked by a hash pointer (Wang, Qin, \& Zhao, 2020). The hash value of the previous block is recorded on the head of the next block (Wang, Qin, \& Zhao, 2020). Any change to that block will cause a series of changes in the subsequent blocks (Wang, Qin, \& Zhao, 2020).

Since its inception, many authors have studied or did research on the blockchain technology and its impact on the audit profession. For instance, Fan, Bao, \& Liu, (2020) replaced the trusted third-party auditor (TPA) with a designed smart contract, a decentralized auditing scheme for blockchain technology companies. Smart contract is a computer trading agreement that agrees on the rules to verify each transaction (Fan, Bao, \& Liu, 2020). Wang, Qin, \& Zhao, (2020) designed a blockchain-based smart contract for public cloud storage auditing. Farooq, Khan, \& Abid, (2020) proposed a blockchain-based charity management platform that aims to provide a transparent and auditable tool. Putz, Menges, Pernul, (2019) proposed an infrastructure that uses a permissioned blockchain to store non-reputable proof of existence for all generated log records. The infrastructure represents a novel software-based solution to the secure logging problem, which does not rely on trusted third parties or modifications to the logging source (Putz, Menges, Pernul, 2019). More and more data owners outsource their data to cloud computing (Fan, Bao, \& Liu, 2020). Data auditing allows the data owner discovering malicious behaviors of cloud service providers (CSP) which destroys their outsourced data (Fan, Bao, \& Liu, 2020). The public auditing authorizes the TPA to audit the owner's outsourced data (Fan, Bao, \& Liu, 2020) using the traditional centralized auditing mechanism. However, it is difficult to find a reliable centralizing auditing which fits to the auditing activities of the organizations which adopted blockchain technology. To fix this problem of trust, and inadequacy between the traditional centralized auditing and the activities of the novel blockchain technology companies, Fan, Bao, \& Liu, (2020) proposed a novel decentralized auditing smart contract in Ethereum where anyone can obtain the auditing result from Ethereum without worrying about semi-honest TPA. Like the bitcoin, Ethereum is another type of cryptocurrency and decentralized application platform (Fan, Bao, \& Liu, 2020). A blockchain is a decentralized 


\section{Issues in Information Systems}

Volume 21, Issue 2, pp. 206-212, 2020

linked data structure that is characterized by its inherent resistance to data modification, but it is deficient in search queries because its data are not formatted. Muzammal, Qu, Nasrulin, (2019) associated distributed database to blockchain to overcome its deficiency in query applications. This is because a distributed database is also a decentralized data structure which features quick query processing and well-designed data formatting (Muzammal, Qu, Nasrulin, 2019). In addition, the blockchain distributed database application platform has the audibility features of the blockchain (Muzammal, Qu, Nasrulin, 2019).

Yet, all the previous research shows that blockchain is more than just a buzzword, as it has the potential to transform how companies and individuals transact with one another. These past studies also demonstrate that Blockchain could not only revolutionize audit processes but will also likely alter the role of auditors. Finally, most of these studies above and in the literature are anecdotal evidence suggesting that blockchain technology will transform auditing by enabling continuous auditing and increasing the auditability of information. However, there is little empirical knowledge of the blockchain implications on the audit profession. The objective of this paper is to explore, through the lens of transaction costs theory, the implications of blockchain technology on the audit profession. A proposed research model will be tested using survey data that will be collected from audit firms. The collected data will be processed using R statistical software that is appropriate to data analytics.

This paper is organized as follows. First, a literature review and evolution of blockchain technology is provided. This description is followed by a research model of how blockchain is transforming auditing. Next, the methodology is analyzed. Then, discussion and expected results for auditors in the blockchain environment are presented. The final section provides concluding remarks.

\section{LITERATURE REVIEW AND EVOLUTION OF BLOCKCHAIN TECHNOLOGY}

\section{Theoretical Background: Transaction Cost Theory}

Ahluwalia, Mahto, \& Guerrero, (2020) examined the economics of blockchain technologies as it pertains to transaction costs in startup financing. Following Ahluwalia, Mahto, \& Guerrero (2020), we draw upon the theory of transaction cost economics to demonstrate the blockchain implications for the audit profession. Concretely, the theory of transaction cost economics model helps to inform how blockchain technologies can influence a firm's organizational decisions because of their ability to decentralize and reduce transactions costs thereby creating trust between the public auditing authority, the trusted TPA, and the auditing companies (Chen, 2018). Blockchain reduces transaction costs, as it allows for transparent and valid transactions (Schmidt \& Wagner, 2019).

Blockchain technology is, "an open, distributed ledger that can record transactions between two parties efficiently and in a verifiable and permanent way" (Iansiti \& Lakhani, 2017). The phrase "distributed ledger" is frequently cited in blockchain definitions, so it is worthwhile to further examine what this phrase entails. Essentially, a distributed ledger is a record of transactions maintained across different locations without the need of a central authority to maintain transaction integrity (Lee, Fiedler, \& Mautz, 2018). This means that instead of relying on a single, authoritative version, many identical full copies of the ledger are stored on multiple nodes.

Different authors have discussed transaction cost theory as an underlying principle that give blockchain its enormous potential to transform the way we transact and interact with each other in a near frictionless manner (Iansiti \& Lakhani, 2017). Generally, when two or more parties wish to transfer value among each other, they rely on a centralized transaction processor, such as a bank to carry out the task. The centralized processor serves as an intermediary between the transacting parties to reduce counterparty risk for each of them. In exchange for centralizing credit risk and ensuring that transactions are executed accurately and securely, the intermediary demands a fee from the transacting parties. By contrast, blockchain works without a centralized processor. As described above, since parties can transact directly with each other, blockchain eliminates the need for intermediaries, thereby drastically reducing transaction costs (Bible, Raphael, \& Riviello, 2017). However, slashing expenses is not the only way blockchain is increasing transaction efficiency. Through enabling near real-time settlements, blockchain also eliminates processing delays and reduces the risk of non-payment (Bible, Raphael, \& Riviello, 2017). Furthermore, as all active nodes maintain a complete copy of the transaction records, blockchain lacks a single point of failure in the event of hacking, thereby greatly enhancing the reliability and security of the network (Bible, Raphael, \& Riviello, 2017). For all these reasons, we can think of blockchain as a "network of 
value" or a "network of trust", in contrast to the Internet, which is simply a "network of information" (Drew, 2018). The following section offers an in-depth analysis of how blockchain is transforming auditing.

\section{How Blockchain Is Transforming Auditing}

Auditors play a vital role in the efficient and effective functioning of the capital markets through enhancing the trust and confidence in the financial information reported by companies they audit. Through applying objectivity and professional skepticism to the engagement, auditors plan and perform the audit to obtain reasonable assurance about whether the financial statements are free from material misstatement, whether due to error or fraud (Bible, Raphael, \& Riviello, 2017). While the need for financial statement audits is undeniable, there are several inherent limitations to the traditional ways of auditing, which may be resolved through blockchain adoption. The following paragraphs examine how blockchain can overcome these drawbacks, as well as how other emerging technologies can be leveraged to complement blockchain-based auditing.

One of the most significant limitations of traditional auditing is that audits are generally completed months after year-end (Carlozo, 2017). This is in stark contrast to today's instant information society in which we live. Waiting 90 days to obtain an opinion on historical numbers is increasingly unacceptable to clients and the users of their financial statements, who expect auditors to provide assurance much closer to the date of transactions (Dai \& Vasarhelyi, 2017; Drew, 2018). Therefore, there is a growing need for continuous, real-time auditing. Blockchain is in an excellent position to significantly improve audit processes in this regard, as it enables near instant verification of transactions. Accordingly, by relying on blockchain technology, audit firms will be able to move away from yearend assessments to continuous online evaluations throughout the year (Psaila, 2017). Diminishing the time lag between transaction and verification dates could also enable auditors to concentrate on more complicated transactions that pose a higher risk of material misstatement, all while routine auditing would be substantially automated. This automation of routine tasks means that many of the time-consuming and labor-intensive data extraction and audit preparation activities could be eliminated (Bible, Raphael, \& Riviello, 2017).

Another serious limitation of traditional auditing is the use of sampling. In order to keep the audit cost-effective, conclusions are often drawn from testing samples of transactions and account balances, instead of whole populations. However, a sample is not always representative of the underlying population, meaning that material misstatements could potentially go undetected even if regulations and professional standards are followed when conducting the audit. Blockchain technology is key to overcoming this limitation by allowing auditors to test the entire population of transactions and account balances within the period under audit. Expanding the coverage of audited items by such an extent will greatly enhance the level of assurance provided by auditors, which in turn will elevate the perception of the audit profession (Psaila, 2017).

An additional limitation of traditional auditing lies in the questionable reliability of supporting documentation. Blockchain can combat this limitation by increasing the auditability of information (Dai \& Vasarhelyi, 2017). Since this technology is immutable, auditors can place much greater trust in documents posted in the blockchain. As purchase orders, invoices, and various other supporting documentation become encrypted and stored in the blockchain, the verification process of reported transactions will become automated (Bible, Raphael, \& Riviello, 2017). For example, with blockchain, the days of highly inefficient, manual third-party confirmations will soon be over. Instead, auditors will be able to quickly verify transactions on public ledgers, which will drastically improve the efficiency and cost effectiveness of audit engagements (Psaila, 2017).

While blockchain alone may revolutionize the audit process, it is not only a disruptor, but it is also a supporter of other disruptors (Drew, 2018). Auditors will only unlock its full potential when blockchain becomes integrated with other emerging technologies. Deploying these technologies together could offer unprecedented synergies to the audit profession. For example, blockchain-based smart contracts could significantly reduce the likelihood for human error and the time auditors spend on reviewing agreements when searching for unrecorded liabilities (Smith, 2018). Furthermore, using machine-learning, data mining, and other analytical tools within the blockchain environment will allow auditors to promptly identify meaningful patterns and investigate troublesome anomalies within their clients' accounting records (Dai \& Vasarhelyi, 2017). Adding automation to this process, relevant parties could receive critical alerts immediately when unusual transactions take place (Bible, Raphael, \& Riviello, 2017). Naturally, this would increase the likelihood that instances of fraud would be uncovered in a timely manner. Yet another technological phenomenon that holds intriguing opportunities for auditors working in a blockchain system is the 
Internet of Things (IoT). For instance, equipping inventory items with location-tracking sensors would enable automatic verification of product delivery to auditors (Drew, 2018). Additionally, IoT sensors could facilitate remote, real-time inventory observations (Dai \& Vasarhelyi, 2017). Sensors could be beneficial not only in determining the location of items but also in evaluating their condition, which would allow auditors to corroborate that inventory is valued properly.

\section{RESEARCH MODEL}

There are five underlying principles that give blockchain its enormous potential to transform the way we transact and interact with each other in a near frictionless manner. These five principles (Figure 1) include distributed database, peer-to-peer transmission, transparency with pseudonymity, irreversibility of records, and computational logic. First, distributed database refers to the fact that the entire database and its history are available to anyone with access to the blockchain, with no single party having complete control. It also means that the need for intermediaries to ensure integrity is eliminated since each party can verify records of transactions directly (Iansiti \& Lakhani, 2017). Second, peer-to-peer transmission indicates that information and resources are shared directly between peers, rather than through a central node (Iansiti \& Lakhani, 2017). Third, transparency with pseudonymity represents the fact that while all transactions are visible to anyone in the blockchain, users have the option of remaining anonymous or revealing their identity as transactions occur between unique blockchain addresses (Iansiti \& Lakhani, 2017). Fourth, irreversibility of records signifies that once transactions are recorded, they cannot be deleted, tampered with, or otherwise altered because they are linked to previous blocks in the chain through a reference to them (Iansiti \& Lakhani, 2017). Finally, computational logic means that by setting up algorithms and rules, blockchain transactions can be automatically triggered (Iansiti \& Lakhani, 2017). These underlying principles give rise to several major benefits to using blockchain technology, including reduced transaction costs and continuous auditing. In our research model, the independent variables are distributed database, peer-to-peer transmission, transparency with pseudonymity, irreversibility of records and computational logic. Those five variables should impact the mediating variable which is reducing transaction cost and the dependent variable which is continuous auditing.

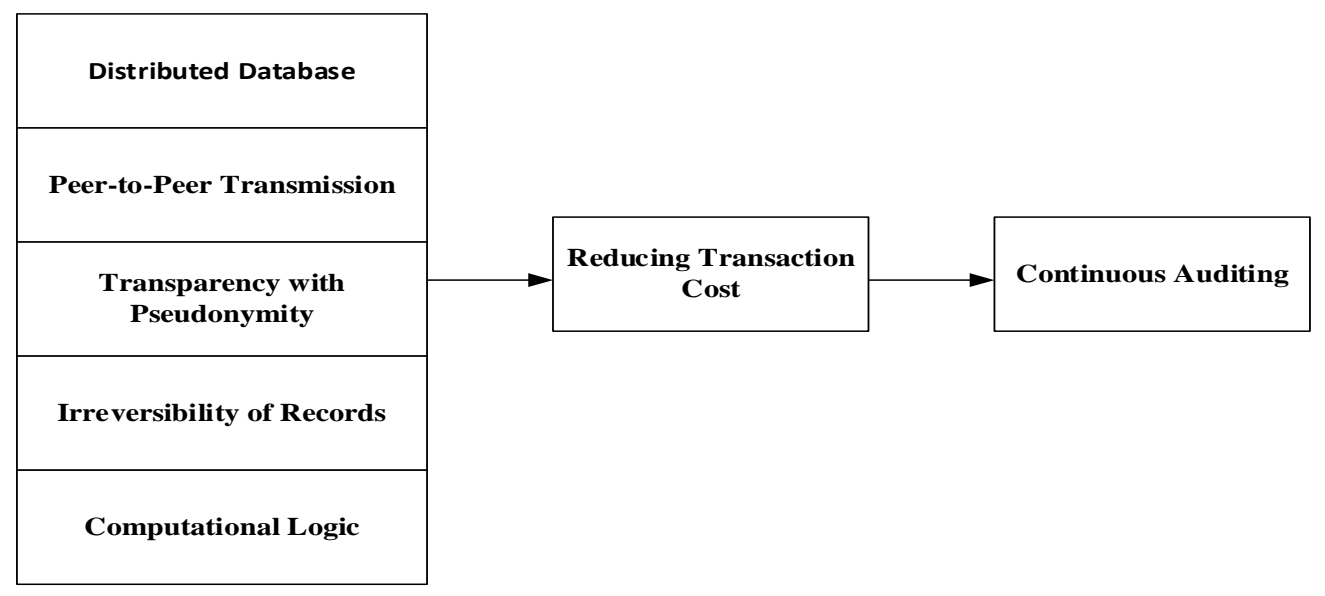

Figure 1. Research Model

\section{METHODOLOGY}

We will perform a survey on audit firms who are actively auditing blockchain companies. The sample would consist of audit firms that have at least audited two or three blockchain companies within a year. For instrument validation purpose, we will first collect existing measurement instruments in the audit profession and review those. We will adapt existing interorganizational information systems (IOS) measurement instruments to the blockchain technology measurement and validate both instruments using Churchill instrument development and validation process.

A pretest will be conducted to assess the face validity of the instrument (Tamandja, Lawson-Body, \& Lawson-Body, 2017). Face validity is the extent to which an instrument is going to measure what it is intended to measure 
(Tamandja, Lawson-Body, \& Lawson-Body, 2017). We will perform a pretest for comprehensiveness and clearness using auditors, as well as representatives of the IT department of the blockchain companies.

The survey will consist of multiple questions relating to each of the factor or variable in the research model. A fivepoint Likert scale ranging from "strongly disagree" (1) to "strongly agree" (5) will be used to measure each variable. A R test will be used to test the model and the questions from the survey.

\section{DISCUSSION AND EXPECTED RESULTS}

Although blockchain may significantly alter financial statement auditing as we know it, this technology will not solve auditors' every trouble.

First, blockchain-enabled auditing does not eliminate the need for professional judgment. While those who are unfamiliar with financial statements might believe that they are statements of facts that report exact measurements, this is rarely the case as information presented by management is often based on approximations and estimates. For example, the net realizable value of accounts receivable hinges on the assessment of allowance for doubtful accounts, which cannot be known with absolute certainty. Therefore, auditors will still be required to apply their professional judgement to evaluate whether the values estimated by the audited company's management are reasonable (Bible, Raphael, \& Riviello, 2017).

Second, while blockchain could very well provide reasonable assurance related to some financial statement assertions, it might not do so concerning others. For example, as transactions are captured by the blockchain, the auditor may have sufficient appropriate audit evidence with respect to the occurrence assertion. Yet, there is no guarantee that a transaction recorded in the blockchain will go into the proper accounts, which means that there is no assurance provided about the classification assertion (Bible, Raphael, \& Riviello, 2017). What is more, since there might be a lack of sufficient appropriate audit evidence regarding the nature of deals, blockchain transactions could still be "unauthorized, fraudulent or illegal" (Bible, Raphael, \& Riviello, 2017). In addition, auditors must obtain an understanding whether transactions in the blockchain are executed at an arm's length and are not linked to off-ledger side agreements (Bible, Raphael, \& Riviello, 2017). These issues are crucial for auditors to consider as they could lead to material misstatements in the financial statements.

Third, since blockchain is still in the adoption stage, it might not be as secure as we would like to think it is. Unfortunately, if there are only a limited number of participants, as is often the case with permissioned blockchains, the risk of collusion is much greater. This means that it is a lot easier to introduce fraudulent transactions into the blockchain (Dai \& Vasarhelyi, 2017). Not having many nodes take part in the system also puts blockchains at risk of "51 percent attacks" (Dai et al. 2017). In such cases, the attacker controls most of the computing power in the network, which allows them to validate fraudulent transactions without even colluding with another blockchain participant. This would make it nearly impossible for auditors to rely on audit evidence obtained from the blockchain, as they would not be able to tell legitimate and fake transactions apart from each other. The only way to overcome this limitation is to have more entities join the network, making it harder for any one or a few participants to hijack the entire system (Dai, Wang, \& Vasarhelyi, 2017). However, the complexity of the technology and need for significant up-front investments are currently hindering wide-spread blockchain adoption (Dai \& Vasarhelyi, 2017).

\section{CONCLUSION}

Blockchain technology offers many benefits that are going to revolutionize the audit profession, from increasing the efficiency of audit processes to creating new roles for auditors. This paper explored several ways in which auditors might overcome the limitations of traditional auditing through utilizing blockchain technology. While the benefits of blockchain-enabled auditing are clear, this paper also investigated some of its limitations. Yet, rather than dwelling on the drawbacks, auditors should embrace this emerging technology and prepare themselves for the new roles presented by blockchain. Although it is wise to have a healthy level of skepticism towards new technologies, the future of the audit profession looks promising in the world of blockchain.

While blockchain will likely revolutionize auditing, it will not eliminate the need for auditors. Four potential roles that a future auditor might take on include auditor of smart contracts, service auditor of consortium blockchains, 
access-granting administrator, and arbitrator (Tysiac, 2018). Regardless of the role they might choose to fulfill, auditors must keep up to date with the technology if they are to stay in-demand in the world of blockchain (Bible, Raphael, \& Riviello, 2017).

\section{REFERENCES}

Ahluwalia, S., Mahto, R. V. and Guerrero, M. (2020). Blockchain technology and startup financing: A transaction cost economics perspective. Technological Forecasting and Social Change, Vol 151, 119854.

Bible, W., Raphael, J., Riviello, M., Taylor, P., \& Oris Valiente, I. (2017). Blockchain technology and its potential impact on the audit and assurance profession. Retrieved from https://www.aicpa.org/content/dam/aicpa/interestareas/frc/assuranceadvisoryservices/downloadabledocume nts/blockchain-technology-and-its-potential-impact-on-the-audit-and-assurance-profession.pdf

Carlozo, L. (2017). Why CPAs need to get a grip on blockchain. Journal of Accountancy. Retrieved from https://www.journalofaccountancy.com/news/2017/jun/blockchain-decentralized-ledger-system$\underline{201716738 . h t m l}$

Chen Y. (2018). Blockchain tokens and the potential democratization of entrepreneurship and innovation. Business Horizons. Vol 61, Issue 4, pp. 567-575.

Dai, J., \& Vasarhelyi, M. A. (2017). Toward blockchain-based accounting and assurance. Journal of Information Systems, 31(3), 5-21. doi:10.2308/isys-51804

Dai, J., Wang, Y., \& Vasarhelyi, M. A. (2017). Blockchain: An emerging solution to prevent fraud. The CPA Journal, 87(6), 12-14. Retrieved from https://ezproxy.library.und.edu/login?url=https://search.ebscohost.com/login.aspx?direct=true\&db=keh\&A $\underline{\mathrm{N}=123973389 \& \text { site }=\text { ehost-live\&scope }=\text { site }}$

Drew, J. (2018). Paving the way to a new digital world. Journal of Accountancy. Retrieved from https://www.journalofaccountancy.com/issues/2018/jun/accounting-technology-roundtable.html

Fan, k., Bao, Z., Liu, M., Vasilakos, A. V., Shi, W. (2020). Dredas: Decentralized, reliable and efficient remote outsourced data auditing scheme with blockchain smart contract for industrial IoT. Future Generation Computer Systems.

Farooq, M. S., Khan, M., and Abid, A. (2020). A framework to make charity collection transparent and auditable using blockchain technology. Computers and Electrical Engineering. Vol 83. 106588.

Iansiti, M., \& Lakhani, K. R. (2017). The truth about blockchain. Harvard Business Review. Retrieved from https://hbr.org/2017/01/the-truth-about-blockchain

Lee, L., Fiedler, K., \& Mautz, R. (2018). Internal audit and the blockchain. Internal Auditor, 75(4), 41-45. Retrieved from https://ezproxy.library.und.edu/login?url=https://search.ebscohost.com/login.aspx?direct=true\&db=keh\&A $\underline{\mathrm{N}=131118307 \& \text { site}=\text { ehost-live\&scope=site }}$

Marr, B. (2018). Here are 10 industries blockchain is likely to disrupt. Forbes. Retrieved from https://www.forbes.com/sites/bernardmarr/2018/07/16/here-are-10-industries-blockchain-is-likely-todisrupt/\#a516a93b5a24

Muzammal, M., Qu, Q., and Nasrulin, B. (2019). Renovating blockchain with distributed databases: An open source system. Future Generation Computer Systems. Vol. 90. pp. 107-117. 
Psaila, S. (2017). Blockchain: A game changer for audit processes? Retrieved from https://www2.deloitte.com/mt/en/pages/audit/articles/mt-blockchain-a-game-changer-for-audit.html

Putz, B., Menges, F., and Pernul, G. (2019). A secure and auditable logging infrastructure based on a permissioned blockchain. Computers \& Security. Vol 87. 101602.

Schmidt, C. G. and Wagner, S. M. (2019). Blockchain and supply chain relations: A transaction cost theory perspective. Journal of Purchasing and Supply Management. Vol 25, issue 4, 100552.

Smith, S. S. (2018). Blockchain augmented audit - Benefits and challenges for accounting professionals. Journal of Theoretical Accounting Research, 14(1), 117-137. Retrieved from https://ezproxy.library.und.edu/login?url=https://search.ebscohost.com/login.aspx?direct=true\&db=bth\&A $\underline{\mathrm{N}=131747318 \& \text { site }=\text { ehost-live } \& \text { scope }=\text { site }}$

Tamandja, E., Lawson-Body, A., Lawson-Body, L., and Jun, L. (2017). Factors affecting virtual gifts acceptance: Mediating roles of hedonic and utilitarian values. Issues in Information Systems Vol 18, Issue 1, pp. 156163.

Tysiac, K. (2018). How blockchain might affect audit and assurance. Journal of Accountancy. Retrieved from https://www.journalofaccountancy.com/news/2018/mar/how-blockchain-might-affect-audit-assurance201818554.html

Wang, H., Qin, H., Zhao, M., Wei, X., Shen, H., and Susilo W. (2020). Blockchain-based fair payment smart contract for public cloud storage auditing. Information Sciences. Vol 519, pp. 348-362. 